\title{
Time constraints on experimental studies of lead apatites
}

\author{
Justyna TOPOLSKA ${ }^{1, *}$, Tomasz BAJDA ${ }^{1}$, Bartosz PUZIO ${ }^{1}$, \\ Maciej MANECKI ${ }^{1}$ and Gabriela KOZUB-BUDZYN ${ }^{1}$ \\ 1 AGH University of Science and Technology, Faculty of Geology, Geophysics and Environmental Protection, \\ Al. Mickiewicza 30, 30-059, Kraków, Poland
}

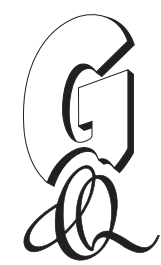

Topolska, J., Bajda, T., Puzio, B., Manecki, M., Kozub-Budzyń, G., 2019. Time constraints on experimental studies of lead apatites. Geological Quarterly, 63 (4): 721-728, doi: 10.7306/gq.1502

Associate Editor: Jacek Szczepański

The paper presents the results of experimental studies on the synthesis and thermodynamic stability of selected Pb-apatites in terms of criteria determining termination of the experiments. Based on the case study, we indicate difficulties in analysing the obtained experimental data. Time-resolved sampling of precipitate formed during a dropwise synthesis of pyromorphite was performed and the results were compared to the literature data. It has been concluded that the Ostwald ripening time for synthesized solids depends primarily on the chemical composition of the intended Pb-apatite phase. We presented that heterogeneity of precipitate affects its dissolution in terms of repeatability of the results and equilibrating time. A unique 9 -year-long experiment on vanadinite stability at a $\mathrm{pH}$ range from 2.0-6.0 revealed that among all tested dissolution conditions only the reactions at the $\mathrm{pH}=3.5$ can perform as the basis for some thermodynamic calculations. It has been concluded that the rate of phase transitions in the $\mathrm{Pb}$-apatites group can be misleading in terms of determining the equilibrium of the system, and the experimental setup designed particularly to provide reliable controls in this aspect should be involved. Means in this respect have been proposed.

Key words: pyromorphite, vanadinite, experimental mineralogy, dissolution, solubility synthesis.

\section{INTRODUCTION}

Apatites are a large group of ubiquitous minerals with broad applications. Their flexible structure can assimilate nearly half of the elements from the Periodic Table (Pan and Fleet, 2002). Therefore, they show a wide range of crystal forms and colours, and are often confused with other minerals (Rakovan and Pasteris, 2015). As the basic component of bones and teeth, apatites are literally close to every single human being (LeGeros, 2008; Pasteris et al., 2008), whereas as one of the main ores of phosphorus and REE, they also play an important role in global economy (Filippelli, 2008). The ability of apatites to immobilize metals in the structure and a wide range of environmental conditions in which these phases are stable determine their possible application in technologies for groundwater and soil treatment (Ma et al., 1993, 1995; Magalhăes and Williams, 2007).

\footnotetext{
* Corresponding author, e-mail: topolska@agh.edu.pl Received: January 12, 2019; accepted: July 25, 2019; first published online: December 3, 2019
}

Lead apatites with a general formula: $\mathrm{Pb}_{5}\left(X_{\mathrm{O}_{4}}\right)_{3} Z$ (where $X$ $=\mathrm{P}, \mathrm{V}, \mathrm{As}$ and $\mathrm{Z}=\mathrm{Cl}, \mathrm{OH}, \mathrm{F}, \mathrm{Br}, \mathrm{I})$ are particularly significant in the field of environmental protection. Induced precipitation of these phases is the fundamental concept of the in situ immobilization of $\mathrm{Pb}$ and $\mathrm{As}$ in contaminated soils and wastes (e.g., Cotter-Howells, 1996; Cotter-Howells and Caporn, 1996; Manecki et al., 2000; Campos, 2002; Cao and Ma, 2004; Bajda et al., 2007). Optimization of this treatment method requires extensive research on apatite phases in the field of their identification, crystallization, transformation, structure refinement and thermodynamic stability (e.g., Ma et al., 1994a, b; Flis et al., 2010 , 2011; Bajda, 2010; Baikie et al., 2014; Topolska et al., 2016; Solecka et al., 2018; Puzio et al., 2018). Also, a number of publications on the influence of microorganisms on the stability of $\mathrm{Pb}$-apatites in the environment has been published (e.g., Manecki and Maurice, 2008; Park et al., 2011; Topolska et al., 2013, 2014; Ceci et al., 2015). The research indicates the limitations of P-induced soil remediation treatments. Most of the studies on the implementation of apatites as sequestration agents are based on the methods typical for experimental mineralogy, i.e. synthesizing crystals with parameters similar to those in the environment and then dissolving them with a chosen method to determine the stability and reactivity. In this regard, the key parameter stating on the reliability of the abiotic laboratory results and the possibility of referring them to field 
conditions is the well-determined equilibrium between solids and solutions at the stage of synthesis, as well as during thermodynamic studies.

Besides their many undoubted advantages, the experimental studies are obviously limited by a number of laboratory constraints, among which the duration of the experiment seems to be one of the most fundamental. In this paper, we present our observations on the role of experimental time in conducting research on the $\mathrm{Pb}$-apatites properties. Particular emphasis was placed on its implication on determining the equilibrium of the systems during synthesis and stability experiments.

\section{METHODS}

\section{SYNTHESIS OF PYROMORPHITE}

Synthesis of the solid was carried out at room temperature by dropwise mixing of the aqueous solutions of $\mathrm{Pb}\left(\mathrm{NO}_{3}\right)_{2}, \mathrm{KCl}$, and $\mathrm{K}_{2} \mathrm{HPO}_{4}$ in molar proportions based on the stoichiometry of the pyromorphite $(\mathrm{Pb}: \mathrm{P}: \mathrm{Cl}=5: 3: 1$ molar ratio). Suspension of the forming precipitate was stirred for 5 hours using a mechanical stirrer, and was allowed to settle. The precipitate was sampled periodically for the first 2 weeks and analysed with the use of Scanning Electron Microscopy coupled with Energy Dispersive Spectroscopy (SEM-EDS). After 2 weeks, the precipitate was separated from the solutions by decantation, washed thoroughly several times with redistilled water and acetone, and dried at $110^{\circ} \mathrm{C}$. The synthetic solid was characterized using SEM-EDS and wet chemical analysis. SEM-EDS examinations were conducted using Jeol 5200 at $25 \mathrm{kV}$. For wet chemical analysis, small amount of the precipitate was digested in $0.02 \mathrm{M}$ EDTA. The concentration of $\mathrm{Pb}$ in solution was determined using atomic absorption spectroscopy (AAS), and that of P - using a colorimetric method of Lenoble et al. (2003). The measurements were made with a SAVANTAA AAS spectrometer and a HITACHI U-1800 UV-Vis spectrophotometer. The synthesis yielded fine, white precipitates. Examination by SEM-EDS revealed particles containing $\mathrm{Pb}, \mathrm{P}, \mathrm{O}$ and $\mathrm{Cl}$ as major constituents. Morphology in the form of hexagonal prisms, typical for apatites, was observed (Fig. 1). No secondary phases were detected. The results of wet chemical analysis of the solid yielded composition of the precipitate very close to the stoichiometry of pyromorphite: $\mathrm{Pb}_{5.09}\left(\mathrm{PO}_{4}\right)_{2.94} \mathrm{Cl}$. The deviation from the ideal formula was within an average analytical error estimated by triplicates to $5 \%$ at the $95 \%$ confidence level.

\section{SYNTHESIS OF VANADINITE}

Synthesis of vanadinite was carried out at $90^{\circ} \mathrm{C}$ by dropwise mixing of the aqueous solutions of $\mathrm{Pb}\left(\mathrm{NO}_{3}\right)_{2}, \mathrm{KCl}$ and $\mathrm{NH}_{4} \mathrm{VO}_{3}$ in molar proportions based on the stoichiometry of the vanadinite ( $\mathrm{Pb}: \mathrm{V}: \mathrm{Cl}=5: 3: 1$ molar ratio). Suspension of the forming precipitate was stirred for 5 hours using a mechanical stirrer, and was allowed to settle. After 2 weeks, the precipitate was separated from the solutions by decantation, washed thoroughly several times with redistilled water and acetone, and dried at $110^{\circ} \mathrm{C}$. The synthetic solid was analysed using X-ray powder diffraction (XRD) and SEM-EDS. The XRD patterns were collected with a Philips PW 3020 X'Pert-APD diffractometer system (with a Cu anode and a graphite monochromator)
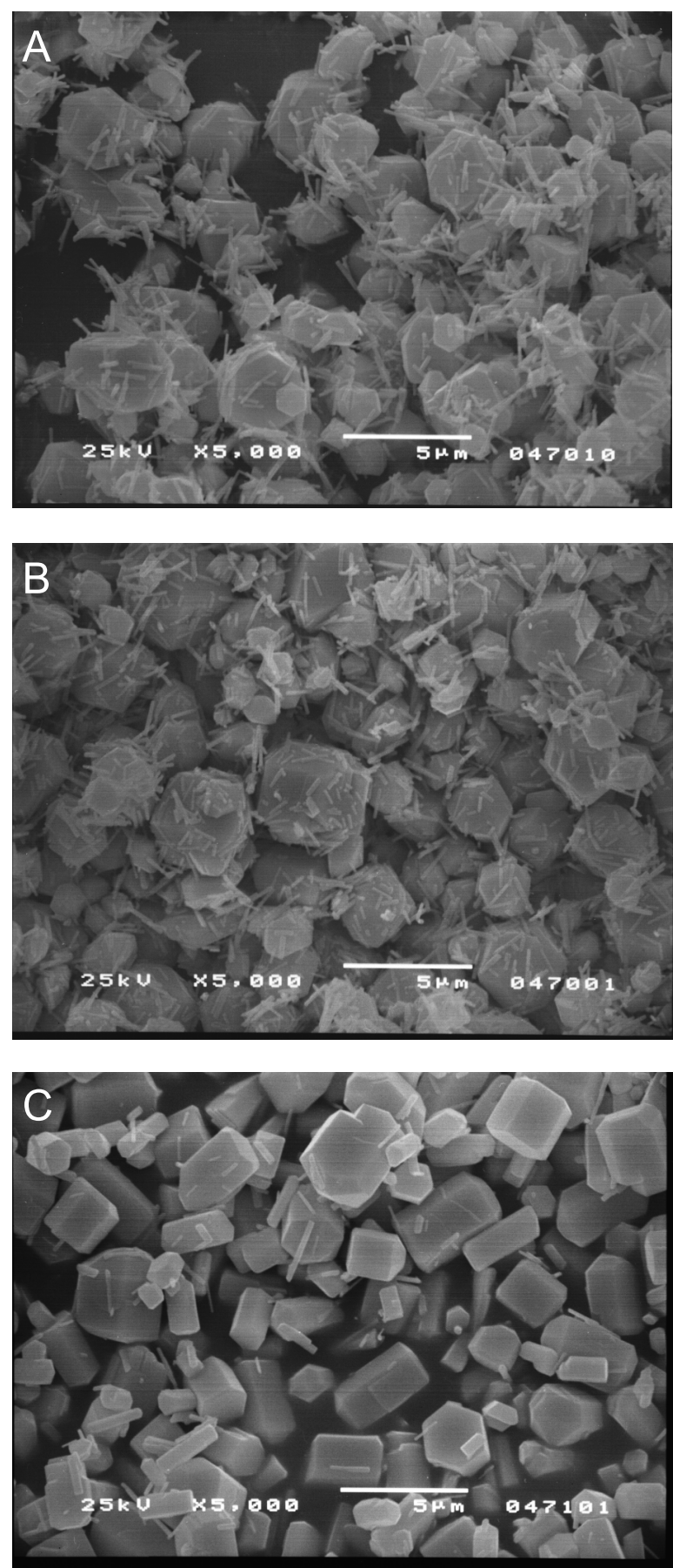

Fig. 1. SEM microphotographs of synthetic pyromorphite

A - precipitate aged for $48 \mathrm{~h}, \mathrm{~B}$ - precipitate aged for 1 week, $\mathbf{C}$ - precipitate aged for 2 weeks

using a step-scan mode at a step size of $0.022 \Theta$ and a rate of 1s per step. A FEI QUANTA 200 FEG was used for the SEM-EDS analysis at $15 \mathrm{kV}$. The synthesis yielded a yellowish homogeneous precipitate. The X-ray powder diffraction data of the synthetic vanadinite sample is presented in the Appendix $1^{*}$. The analysed phase was identified as pure vanadinite.

\footnotetext{
* Supplementary data associated with this article can be found, in the online version, at doi: 10.7306/gq.1502
} 
The SEM-EDS analysis of the precipitates confirmed the XRD results, yielding fine crystals with the size $\sim \leq 2$ um (Fig. 2) and the composition close to vanadinite: $\mathrm{Pb}_{5}\left(\mathrm{VO}_{4}\right)_{2.95} \mathrm{Cl}_{0.95}$ considering the $10 \%$ analytical error estimated based on replicates.

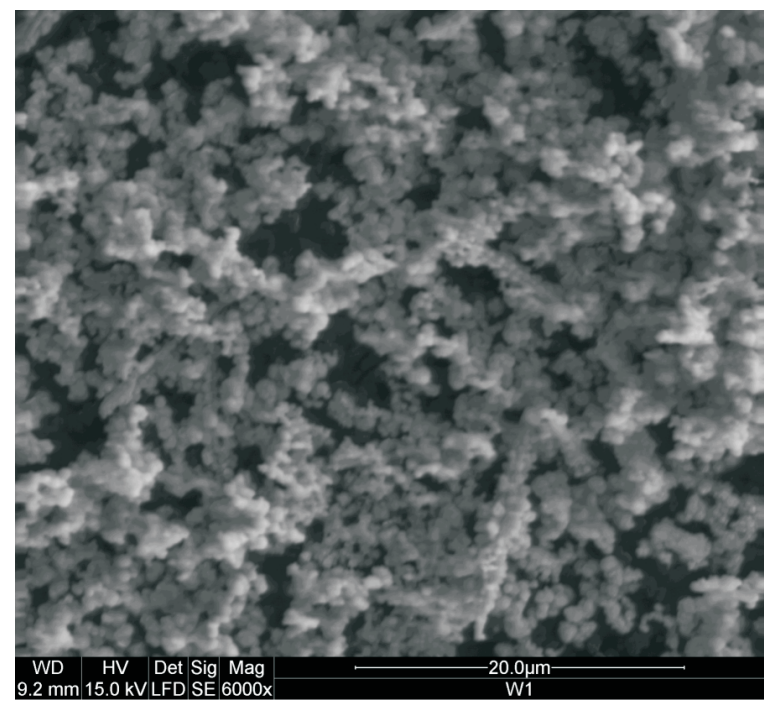

Fig. 2. SEM microphotograph of synthetic vanadinite

The precipitate was aged for 2 weeks

\section{DISSOLUTION OF VANADINITE}

Dissolution experiments were performed in triplicates in 250-mL polycarbonate bottles immersed in a closed water bath with thermostatic control at $25^{\circ} \mathrm{C}$. Equal portions $(150 \mathrm{mg})$ of synthetic vanadinite were washed thoroughly with redistilled water and introduced as a suspension to the bottles containing $250 \mathrm{~mL}$ of $0.05 \mathrm{M} \mathrm{KNO}_{3}$ solution. Totally, there were 7 sets of the experiment with the $\mathrm{pH}$ adjusted, using $0.1 \mathrm{M} \mathrm{HNO}_{3}$, to: 2.0 , $2.5,3.0,3.5,4.0,5.0$ and 6.0. The dissolution was carried out for 8 months. During this time, the bottles were manually stirred at least two times a week, and the solution samples were periodically withdrawn and filtered using a $0.2 \mu \mathrm{m}$ polycarbonate filter. The $[\mathrm{Cl}]$ evolution patterns from the dissolution experiments were observed to determine the equilibrium in the suspensions. $\mathrm{Cl}$ concentration was measured using a turbidimetric method with silver nitrate. The system was considered in equilibrium when at least three consecutive samples showed identical [Cl], with an experimental error expressed as standard deviation of triplicate results. The residual solids were sampled, washed with acetone, air-dried, and characterized with SEM-EDS. Additionally, the residuum from the experiment at $\mathrm{pH}=3.0$ was examined with XRD. After this stage of dissolution experiment, the bottles with the suspensions were transferred to a room temperature of $22 \pm 2^{\circ} \mathrm{C}$ and left for 9 years. The reactors were occasionally mixed and checked for leaks. At the end of the experiments, the concentration of $\mathrm{Cl}$ in solutions was measured by the turbidimetric method with silver nitrate and the residual solids were analysed with the use of SEM-EDS (A FEI QUANTA $200 \mathrm{FEG}$, at $15 \mathrm{kV}$ ).

\section{RESULTS AND DISCUSSION}

\section{TIME-DEPENDENT SYNTHESIS AND ITS IMPLICATIONS ON DISSOLUTION EXPERIMENTS}

Among all $\mathrm{Pb}$-apatites, pyromorphite is a mineral of the best-known properties, as indicated by the number of publications (e.g., Ma et al., 1994a, b; Flis et al., 2010, 2011; Bajda, 2010; Baikie et al., 2014; Topolska et al., 2016). Scheckel and Ryan (2002) reported on the necessity of 24-hour-long aging of the pyromorphite precipitate formed during dropwise synthesis. The results of our experiments confirmed their general conclusions; however, according to our observations in the context of the entire $\mathrm{Pb}$-apatite group, the process seems to be more complex. Figures 1 show the changes in the crystal size of the synthesized pyromorphite precipitate with prolonged time of aging. The samples were collected $48 \mathrm{~h}$ (Fig. 1A), 1 week (Fig. 1B) and 2 weeks (Fig. 1C) after the synthesis was completed. The SEM images clearly show that the number of fine, long, thread-like crystals decreased with time, transforming into stubby crystals of even dimensions according to the Ostwald ripening mechanism (Sordyl et al., 2017). Differences between the precipitate sampled at hour 48 and after 1 week are not well visible. After 2 weeks (Fig. 1C), the precipitate comprised mainly of crystals $\sim>5 \mu \mathrm{m}$ in size; however, some admixture of fine crystals remained. This suggests that proposed by Scheckel and Ryan (2002), lasting 24 hours aging of pyromorphite synthesis is not an universal method to obtain a homogeneous precipitate of this mineral and it certainly should not be used as a criterion for determining the homogeneity of synthesized precipitate for other $\mathrm{Pb}$-apatites. Instead, we propose to observe the Ostwald ripening process for each synthesis experiment individually. Furthermore, as recently suggested by Sordyl et al. (2017), the aging time of synthesized precipitate is individual for each $\mathrm{Pb}$-apatite phase and strongly depends on its chemical composition. As an example confirming conclusions proposed in this study and by Sordyl et al. (2017), we would like to recall here the results presented by our research group (Flis et al., 2011) in the paper on thermodynamic parameters of the pyromorphite-mimetite solid solution series. Figure 3 shows selected data reported previously (Flis et al., 2011), however, with improved resolution achieved by changes in the time scales. This enables to consider the kinetic aspects of the experiment, which have not been discussed so far. The plot presents the time-dependent evolution of $\mathrm{Pb}$ concentration in the solution equilibrating with synthetic: pyromorphite (Fig. 3A), solid solution between pyromorphite and mimetite (Fig. 3B), and mimetite (Fig. 3C) during the dissolution experiments described in Flis et al. (2011). Note that a relatively significant and irregular fluctuation of the $\mathrm{Pb}$ concentration was apparent for the first $300 \mathrm{~h}$. Based on the results of the experiments on the influence of aging time on the homogeneity of synthesized precipitates, presented in this study, it can be concluded that the fluctuations resulted most likely from the fact that the dissolving precipitates contained heterogeneous crystals exhibiting a different rate of dissolution. The synthesized phases used in the experiments had been aged only for 14 days (refer to Flis et al., 2011 for the SEM images). Furthermore, even though all three materials: pyromorphite, solid solution and mimetite, were prepared according to the same synthesis procedure, including 

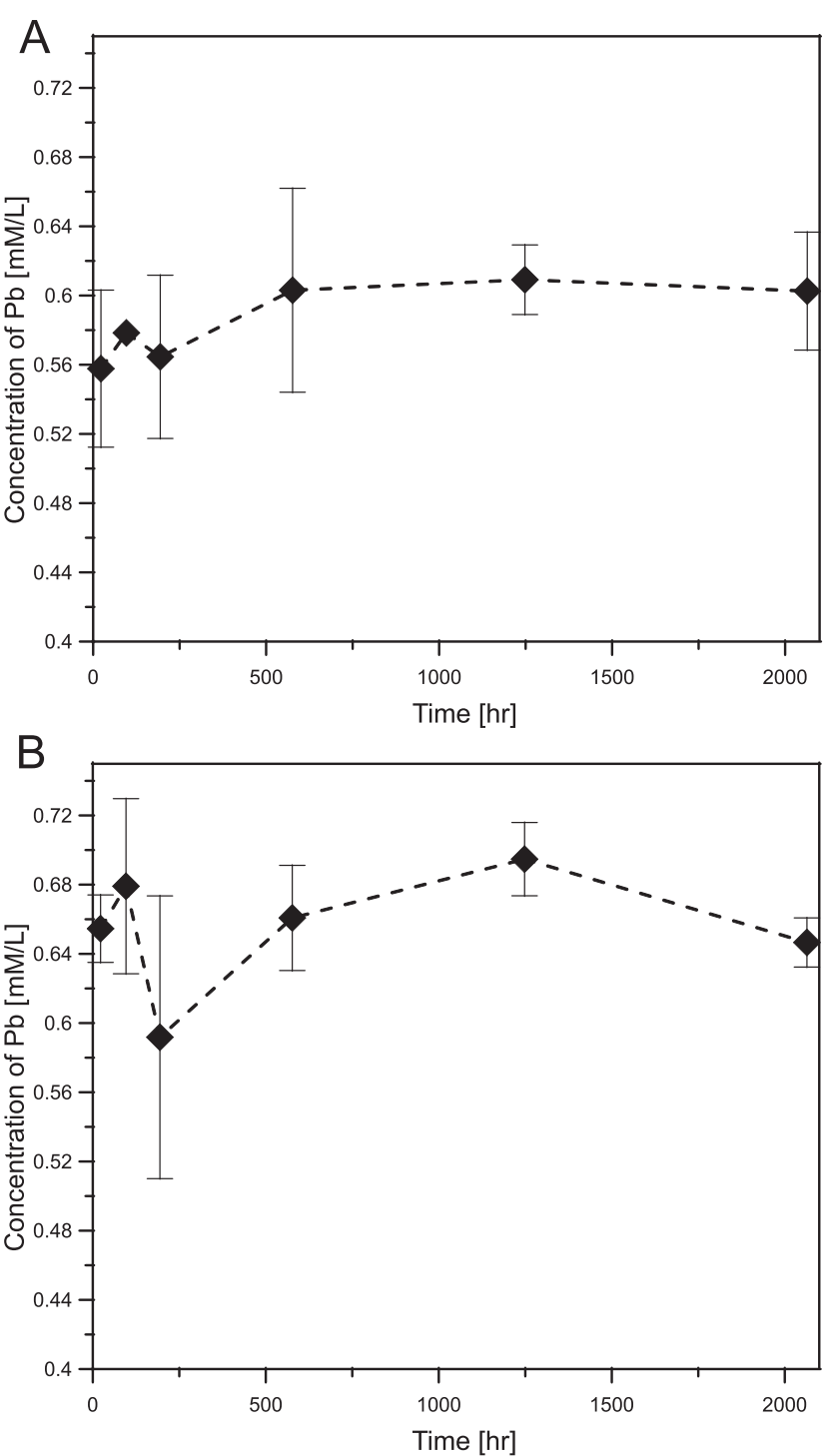

C

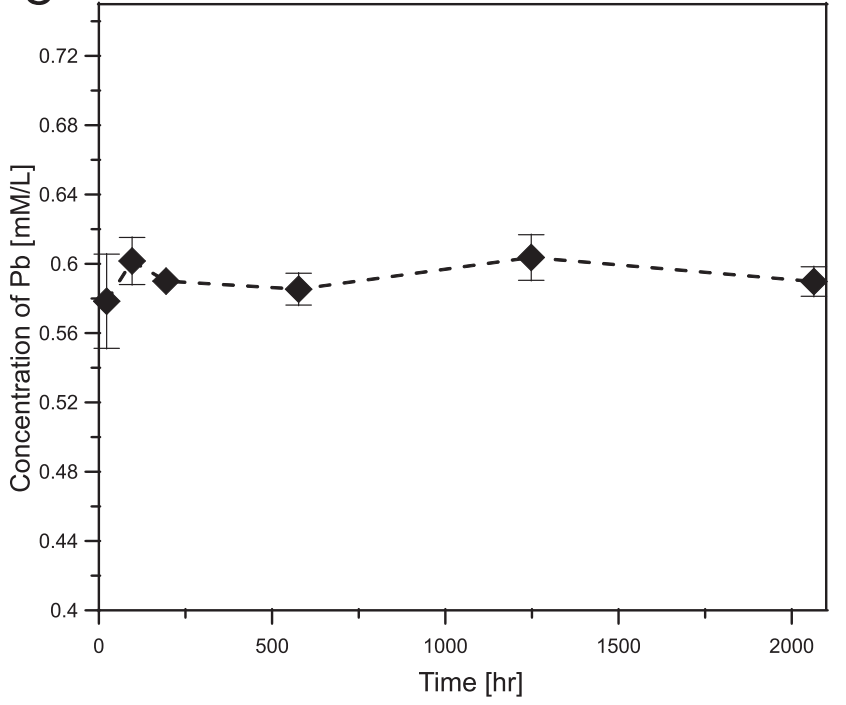

Fig. 3. The evolution of $\mathrm{Pb}$ concentration in the dissolution experiment of pyromorphite (A), pyromorphite-mimetite solid solution (B) and mimetite (C)

Data points represent the average of triplicate experiments, error bars are two standard deviations the aging time, the proportion of small and mature crystals in the final precipitates differed (refer to Flis et al., 2011 for the SEM images) and depended on the chemical composition of the phase, which is consistent with conclusions proposed by Sordyl et al. (2017). We find that this effect had an implication on the further dissolution process and therefore in Figure 3 , the intensity of initial fluctuation of the $\mathrm{Pb}$ concentration is not the same for all phases. It seems that the mimetite precipitate was the most homogeneous, hence the observed changes in dissolved $\mathrm{Pb}$ amounts were least intense in its case and the experiments yielded the most consistent results (small error bars describing triplicates).

Bringing the precipitate to a homogeneous form is particularly important when conducting studies on the kinetics of the dissolution reaction (Scheckel and Ryan, 2002); it is a common knowledge that crystals with a larger surface-to-volume ratio are prone to react with the solution. This phenomenon is slightly less important during experimental studies on thermodynamic properties of $\mathrm{Pb}$-apatites, however, as it results from our experience and is described above, running the dissolution experiments on a heterogeneous solid might affect repeatability of the results and lead to an increased dissolution rate in the initial steps of the reaction. This, in turn, lowers the quality of final conclusions and extends the equilibrating time for the solution.

\section{TIME AND THE EXPERIMENTAL THERMODYNAMICS}

The experimentally determined thermodynamic parameters of pyromorphite, mimetite and their intermediate members have been published in a number of papers (Bajda, 2010; Flis et al., 2010; Topolska et al., 2016). Research on the properties of vanadinite, the third end-member in a solid solution series of anionic substitutions among $\mathrm{Pb}$-apatites (Baker, 1966), is still ongoing and is more problematic. The phosphate, arsenate and vanadate anionic groups are similar to each other in terms of stereochemistry. While the chemical reactivity of $A s$ and $P$ are comparable, $V$ - being a transition metal - exhibits different properties. Unlike phosphate or arsenate anions, vanadate groups tend to polymerize in aqueous solution (Schindler et al., 2000). Hence, a vanadinite $\mathrm{Pb}_{5}\left(\mathrm{VO}_{4}\right)_{3} \mathrm{Cl}$ is prone to recrystallize into a chervetite $\mathrm{Pb}_{2} \mathrm{~V}_{2} \mathrm{O}_{7}$ in a wide range of conditions (Evans and Garrels, 1958). The recrystallization is slow and poorly understood in the context of vanadinite solubility. Experimental determination of the mineral thermodynamic parameters based on its incongruent dissolution is possible if the thermodynamics of the additional phase is known and the state of equilibrium for both phases and the solution is found. To determine the equilibrium conditions for the vanadinite-chervetite system at $25^{\circ} \mathrm{C}$, a series of dissolution experiments of synthetic vanadinite at various $\mathrm{pH}$ was performed for over 9 years. The experimental time was divided into two parts. The 8-months period reflected the standard experimental time for this type of research, during which regular analyses were performed. Then, the experiments were continued for additional 8.5 years, after which the solutions and solids were analysed again to evaluate whether the conclusions from the short-term studies were reasonable. Figure 4 shows the evolution of $\mathrm{Cl}$ concentration in the experimental solutions. The stabilization of $\mathrm{Cl}$ concentration was chosen as a parameter defining the equilibrium in the system, since it is a component of vanadinite, but it does not build into the structure of a potentially forming chervetite. Figure 4 shows the $\mathrm{Cl}$ concentrations in solutions at $\mathrm{pH}=2.0,2.5,3.0$ and 3.5 (note 
the break in the time scale separating the results obtained after 8 months from those obtained after 9 years). Figures 5 and 6 provide SEM microphotographs of the solids after 8 months and 9 years of dissolution, respectively. The EDS analysis (data not shown) indicated that the fine hexagonal crystals belonged to the $\mathrm{Cl}$-rich phase with the ionic proportions corresponding to vanadinite $\mathrm{Pb}_{5}\left(\mathrm{VO}_{4}\right)_{3} \mathrm{Cl}$, while the tabular ones were made of chervetite $\mathrm{Pb}_{2} \mathrm{~V}_{2} \mathrm{O}_{7}$. These results were confirmed by the XRD analysis (data presented in the Appendix 1). All registered peaks were identified as those from vanadinite and chervetite according to the referred data base.

\section{DISSOLUTION OF VANADINITE: IMPLICATION OF THE RESULTS OF 8-MONTH RESEARCH}

The experiment was conducted at a $\mathrm{pH}$ range from 2.0 to 6.0 , however, during the first 8 months, the concentration of $\mathrm{Cl}$ in the solutions with $\mathrm{pH} \geq 4.0$ was below the detection limit. As presented in Figure 4, the concentration of $\mathrm{Cl}$ in all other experimental solutions indicated the potential equilibrium in the system, i.e. the samples collected in $2200 \mathrm{~h}, 3200 \mathrm{~h}$ and 4000 $\mathrm{h}$ of the experiment yielded values identical within the experimental error (verified with the use of a Student's $t$-test, at $\alpha=$ 0.05). Three consecutive analyses performed for a solution over a period of several weeks, revealing statistically identical concentration values, are usually a sufficient criterion to recognize the equilibrium of the system (e.g., Topolska et al., 2016). Therefore, the residue was sampled and analysed using SEM. As presented in Figure $5 \mathrm{~A}$ and $\mathrm{B}$, vanadinite was not present in the suspensions at $\mathrm{pH}=2.0$ or 2.5 : it seemed that the conversion of the mineral into chervetite occurred relatively fast and was complete at this point. Therefore, these experimental conditions were excluded as meeting the requirements for further thermodynamic calculations. However, the

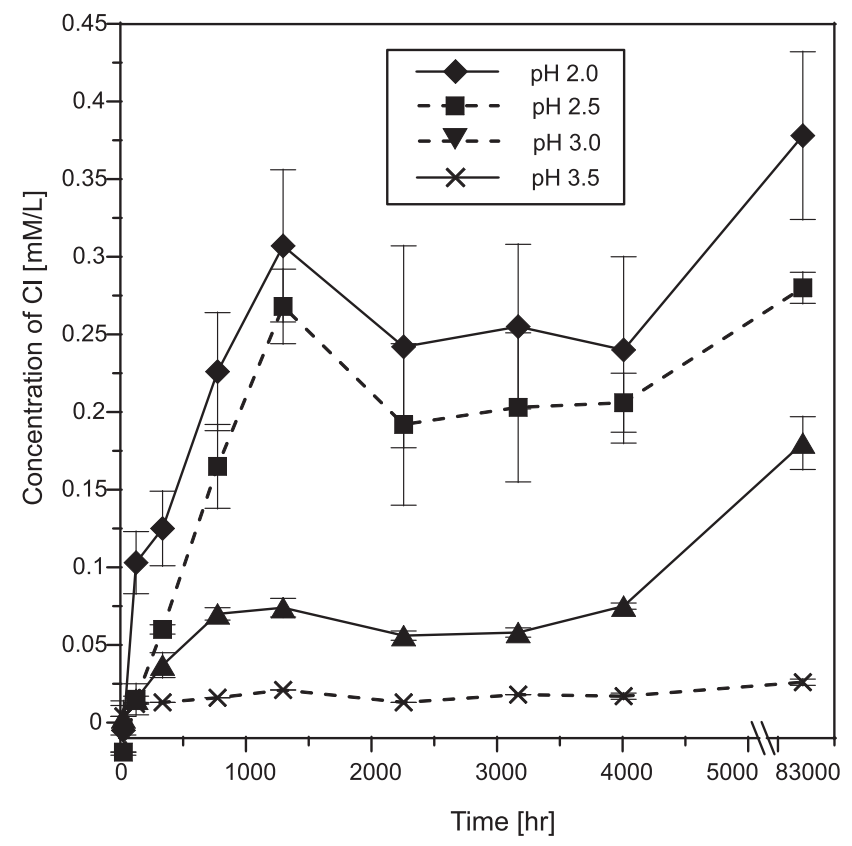

Fig. 4. The evolution of $\mathrm{Cl}$ concentration in the dissolution experiment of vanadinite

Data points represent the average of triplicate experiments, error bars are two standard deviations amount of chervetite in the suspensions with dissolving vanadinite decreased with increasing $\mathrm{pH}$. As indicated in Figure 5D and $\mathrm{E}$, at pH 5.0 and 6.0, the precipitate was lacking visible admixtures of chervetite and consisted totally of pure vanadinite crystals (within the detection limits of the methods used). This suggested the potentially congruent nature of vanadinite dissolution at these conditions. However, the geochemical modelling using PHREEQC (Parkhurst, 1995) did not confirm this interpretation (data not shown). The results of the solution and sediment analysis obtained for the experiments at $\mathrm{pH}=3.0$ and 3.5 indicated a stable equilibrium state in which both vanadinite and chervetite were present. Hence, these experiments were selected as potential for estimating the solubility product of vanadinite.

\section{DISSOLUTION OF VANADINITE: IMPLICATION} OF RESULTS OF 9-YEAR RESEARCH

The experimental suspensions described above were kept for a period of 9 years. The reactors were sealed, occasionally mixed, and the temperature was reduced from $25^{\circ} \mathrm{C}$ to room temperature $\sim 22 \pm 2^{\circ} \mathrm{C}$. This ensured a quality of the long-term experiment, so that the effect of potential evaporation after 9 years was negligible. The last points on the graph presented in Figure 4 show the concentration of $\mathrm{Cl}$ in the samples collected after 9 years. The elevated amounts of $\mathrm{Cl}$ in the solutions with $\mathrm{pH} 2.0$ and 2.5 indicate that, contrary to the assumptions, the recrystallization of vanadinite into chervetite under these conditions had not been completed after 8 months. Similarly, the solution at $\mathrm{pH}=3.0$ had not been in equilibrium, but rather in a metastable state. It is also worth mentioning that, after 9 years, $\mathrm{Cl}$ appeared as well in the solutions with an initial $\mathrm{pH}$ of 4.0-6.0, for which it was below the detection limit before. After completing the research ( 9 years), the concentrations of $\mathrm{Cl}$ in these solutions were (in $\mathrm{mM}$ ) $0.031 \pm 0.004,0.021 \pm 0.01$ and $0.013 \pm 0.006$ for $\mathrm{pH}=4.0,5.0$ and 6.0 , respectively. Furthermore, contrary to the state that had occurred in the 8th month of the experiments, after 9 years of studies, the solid residue at $\mathrm{pH}=5.0$ and 6.0 (presented in Figure 6F and G, respectively) did not consist of pure vanadinite, but some evident admixture of chervetite appeared (tabular chervetite crystals are particularly evident in Figure 6F' and 'G' which show microphotographs taken at higher magnification). These observations denied the previous conclusions that vanadinite had dissolved congruently under these conditions; the recrystallization was indeed ongoing, but the reaction rate was reduced by orders of magnitude with increasing $\mathrm{pH}$, which led to misleading conclusions after 8 months of experiment. In terms of stability, among all tested dissolution conditions, the exception was at $\mathrm{pH} 3.5$, for which a Student's $t$-test showed that the $\mathrm{Cl}$ concentrations sampled at hours 1,200, 1,300 and 83,000 of the experiment were statistically identical (at $\alpha=0.05$ ). The longterm experiments have demonstrated unambiguously that, despite observed $\mathrm{Cl}$ fluctuations in this solution, the reactions can perform as the basis for some thermodynamic estimates.

\section{CONCLUSIONS}

The presented research shows that the aging time for the $\mathrm{Pb}$-apatite precipitates which formed during dropwise synthesis depends not only on the experimental conditions, but primarily on the chemical composition of the synthesized phase. 

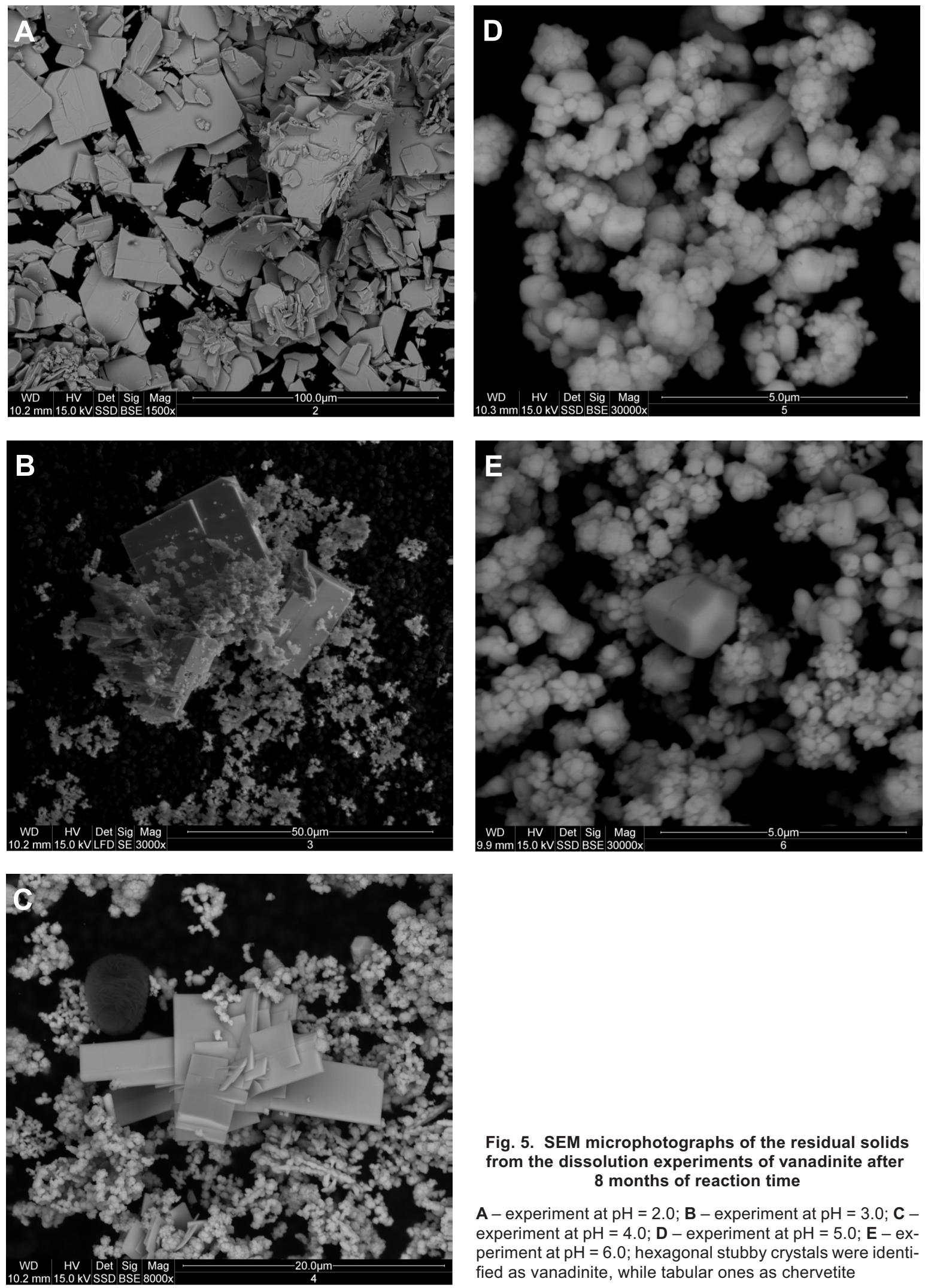

Fig. 5. SEM microphotographs of the residual solids from the dissolution experiments of vanadinite after 8 months of reaction time

A - experiment at $\mathrm{pH}=2.0 ; \mathbf{B}-$ experiment at $\mathrm{pH}=3.0 ; \mathbf{C}-$ experiment at $\mathrm{pH}=4.0 ; \mathbf{D}$ - experiment at $\mathrm{pH}=5.0 ; \mathbf{E}-$ experiment at $\mathrm{pH}=6.0$; hexagonal stubby crystals were identified as vanadinite, while tabular ones as chervetite 

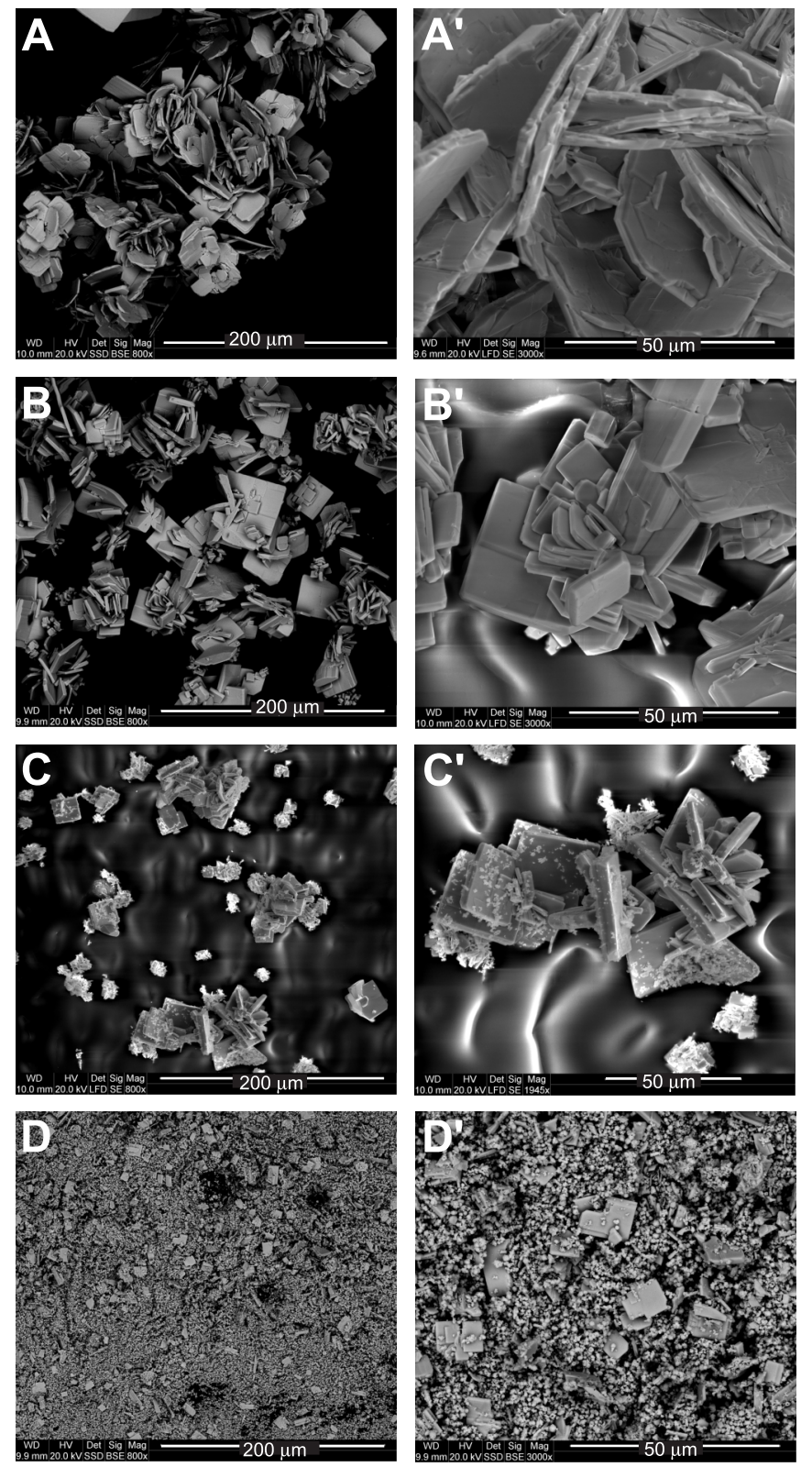

Heterogeneity of a solid affects its dissolution in terms of repeatability of the results and equilibrating rate. Therefore, special attention to the Ostwald ripening time should be paid for each synthesized phase individually. The unique, 9-year-long experiments on vanadinite dissolution revealed that the rate of transformation and recrystallization within this group of minerals may be so slow that, with faulty assumptions on the duration of experiment, the metastable state can be evaluated as equilibrium. The obtained results indicate that, due to the recrystallization of vanadinite into chervetite, among all tested dissolution conditions only the reactions occurring at the $\mathrm{pH}=$ 3.5 can be reliably used as the basis for some further thermodynamic estimations. Since it is not always possible to con-
Fig. 6. SEM microphotographs of the residual solids from the dissolution experiments of vanadinite after 9 years of reaction time

A, A'- experiment at $\mathrm{pH}=2.0 ; \mathbf{B}, \mathbf{B}^{\prime}-$ experiment at $\mathrm{pH}=2.5 ; \mathbf{C}^{\prime} \mathbf{C}^{\prime}$ - experiment at $\mathrm{pH}=3.0$; D, D' - experiment at $\mathrm{pH}=3.5 ; \mathbf{E}, \mathbf{E}^{\prime}-$ experiment at $\mathrm{pH}=4.0 ; \mathbf{F}, \mathbf{F}^{\prime}$ - experiment at $\mathrm{pH}=5.0 ; \mathbf{G}, \mathbf{G}^{\prime}$ - experiment at $\mathrm{pH}=6.0$; magnifications of selected places in the main photographs were marked with apostrophes following the letters; hexagonal stubby crystals were identified as vanadinite, while tabular ones as chervetite
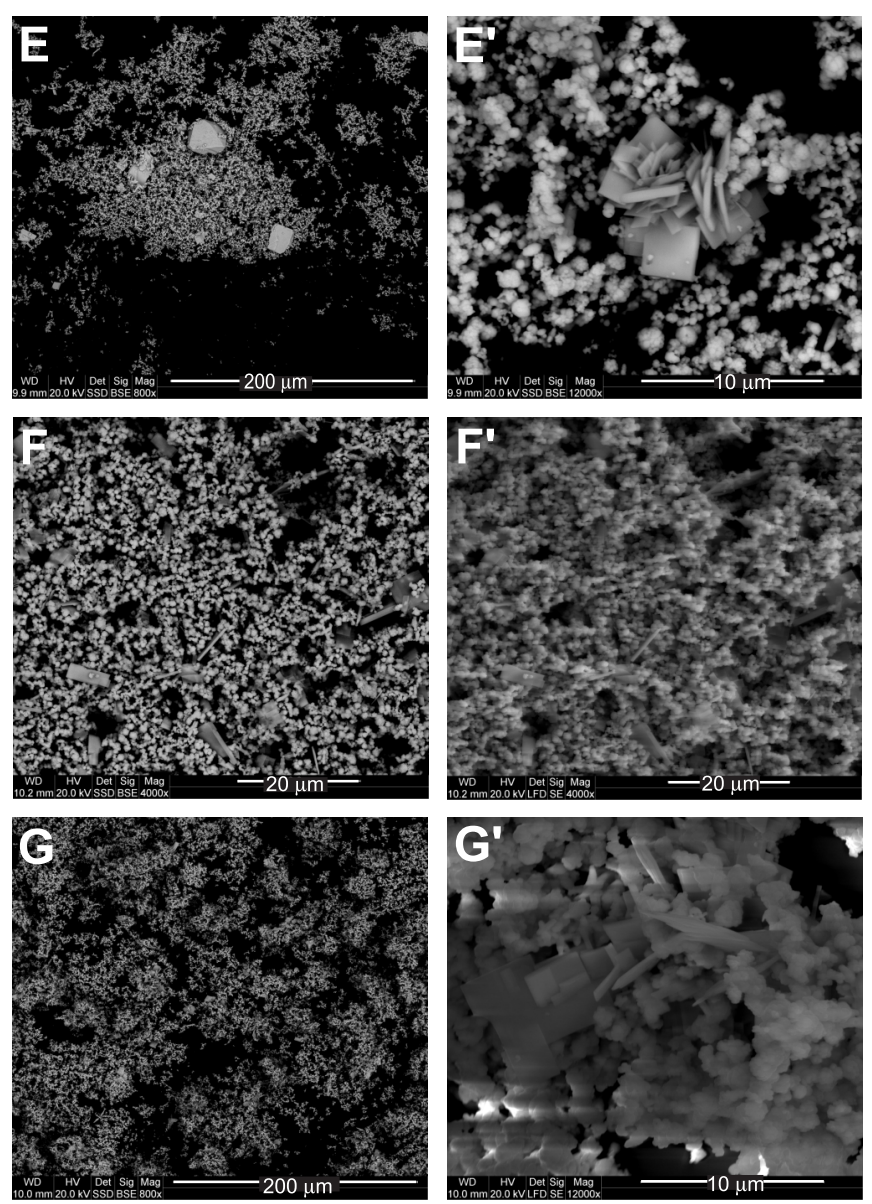

duct long-term research, some other means ensuring reliable determination of equilibrium in the system should be provided by the experimental setup. One of the ways to avoid mistakes is to run parallel precipitation and dissolution experiments for the same conditions, as presented in one of our previous papers (Flis et al., 2011).

Acknowledgement. This work was funded by the AGH University of Science and Technology statutory project No. 11.11.140.158. We would like to thank the reviewers: Dr. O. Borkiewicz and Prof. J. Janeczek for their contribution to the final shape of the manuscript. 


\section{REFERENCES}

Baikie, T., Schreyer, M., Wei, F., Herrin, J.S., Ferraris, C., Brink, F., Topolska, J., Piltz, R.O., Price, J., White, T.J., 2014. The influence of stereochemically active lone-pair electrons on crystal symmetry and twist angles $\mathrm{n}$ lead apatite-2H type structures. Mineralogical Magazine, 78: 325-345.

Bajda, T., 2010. Solubility of mimetite $\mathrm{Pb}_{5}\left(\mathrm{AsO}_{4}\right)_{3} \mathrm{Cl}$ at $5-55^{\circ} \mathrm{C}$. Environmental Chemistry, 7: 268-278.

Bajda, T., Szmit, E., Manecki, M., 2007. Removal of As(V) from solutions by precipitation of mimetite $\mathrm{Pb}_{5}\left(\mathrm{AsO}_{4}\right)_{3} \mathrm{Cl}$. In: Environmental Engineering (eds. L. Pawłowski, M. Dudzińska and A. Pawłowski): 119-124. Taylor and Francis, New York, Singapore.

Baker, W.E., 1966. An X-ray diffraction study of synthetic members of the pyromorphite series. American Mineralogist, 51: $1712-1721$.

Campos, V., 2002. Arsenic in groundwater affected by phosphate fertilizers at Săo Paulo, Brazil. Environmental Geology, 42: $83-87$.

Cao, X., Ma, L.Q., 2004. Effect of compost and phosphate on plant arsenic accumulation from soils near pressure-treated wood. Environmental Pollution, 132: 435-442.

Ceci, A., Kierans, M., Hillier, S., Persiani, A.M., Gadd, G.M., 2015. Bioweathering of mimetite and a general geomycological model for lead apatite mineral biotransformations. Applied and Environmental Microbiology, 81: 4955-4964.

Cotter-Howells, J., 1996. Lead phosphate formation in soils. Environmental Pollution, 93: 9-16.

Cotter-Howells, J., Caporn, S., 1996. Remediation of contaminated land by formation of heavy metal phosphates. Appied Geochemistry, 11: 335-342.

Dai, Y.S., Hughes, J.M., 1989. Crystal-structure refinements of vanadinite and pyromorphite. Canadian Mineralogist, 27: 189-192.

Evans, H.T., Jr., Garrels, R.M., 1958. Thermodynamic equilibria of vanadium in aqueous systems as applied to the interpretation of the Colorado Plateau ore deposits. Geochimica et Cosmochimica Acta, 15: 131-149.

Filippelli, G.M., 2008. The global phosphorus cycle: past, present and future. Elements, 4: 89-95.

Flis, J., Borkiewicz, O., Bajda, T., Manecki, M., Klasa, J., 2010 Synchrotron-based X-ray diffraction of the lead apatite series $\mathrm{Pb}_{10}\left(\mathrm{PO}_{4}\right)_{6} \mathrm{Cl}_{2}-\mathrm{Pb}_{10}\left(\mathrm{AsO}_{4}\right)_{6} \mathrm{Cl}_{2}$. Journal of Synchrotron Radiation, 17: 207-214.

Flis, J., Manecki, M., Bajda, T., 2011. Solubility of pyromorphite $\mathrm{Pb}_{5}\left(\mathrm{PO}_{4}\right)_{3} \mathrm{Cl}$ - mimetite $\mathrm{Pb}_{5}\left(\mathrm{AsO}_{4}\right)_{3} \mathrm{Cl}$ solid solution series. Geochimica et Cosmochimica Acta, 75: 1858-1868.

LeGeros, R.Z., 2008. Calcium phosphatebased osteoinductive materials. Chemical Reviews, 108: 4742-4753.

Lenoble, V., Deluchat, V., Serpaud, B., Bollinger, J.C., 2003. Arsenite oxidation and arsenate determination by the molybdene blue method. Talanta, 61: 267-276.

Ma, Q.Y., Traina, S.J., Logan, T.J., Ryan, J.A., 1993. In situ lead immobilization by apatite. Environmental Science and Technology, 27: 1803-1810.

Ma, Q.Y., Logan, T.J., Traina, S.J., Ryan, J.A., 1994a. Effects of $\mathrm{NO}^{3-}, \mathrm{Cl}^{-}, \mathrm{F}^{-}, \mathrm{SO}_{4}{ }^{2-}$, and $\mathrm{CO}_{3}{ }^{2-}$ on $\mathrm{Pb}^{2+}$ immobilization by hydroxyapatite. Environmental Science and Technology, 28: 408-418.

Ma, Q.Y., Traina, S.J., Logan, T.J., Ryan, J.A., 1994b. Effect of aqueous $\mathrm{Al}, \mathrm{Cd}, \mathrm{Cu}, \mathrm{Fe}(\mathrm{II}), \mathrm{Ni}$, and $\mathrm{Zn}$ on $\mathrm{Pb}$ immobilization by hydroxyapatite. Environmental Science and Technology, 28: 1219-1228.
Ma, Q.Y., Logan, T.J., Traina, S.J., 1995. Lead immobilization from aqueous solutions and contaminated soils using phosphate rocks. Environmental Science and Technology, 29: 1118-1126.

Magalhăes, M.C.F., Williams, P.A., 2007. Apatite group minerals: solubility and environmental remediation. In: Thermodynamics, Solubility and Environmental Issues (ed. T.M. Letcher): 327-342. Elsevier, New York.

Manecki, M., Maurice, P.A., 2008. Siderophore promoted dissolution of pyromorphite. Soil Science, 173: 82-830.

Manecki, M., Maurice, P.A., Traina S.J., 2000. Uptake of aqueous $\mathrm{Pb}$ by $\mathrm{Cl}^{-}, \mathrm{F}^{-}$, and $\mathrm{OH}^{-}$apatites: mineralogic evidence for nucleation mechanism. American Mineralogist, 85: 932-942.

Pan, Y., Fleet, M.E., 2002. Phosphates: geochemical, geobiological, and materials importance. Reviews in Mineralogy and Geochemistry, 48: 13-49.

Park, J.H., Bolan, N., Megharaj, M., Naidu, R., 2011. Isolation of phosphate solubilizing bacteria and their potential for lead immobilization in soil. Journal of Hazardous Materials, 185: 829-836.

Parkhurst, D.L., 1995. User's guide to PHREEQC - a computer program for speciation, reaction-path, advective-transport, and inverse geochemical calculations. U.S. Geological Survey Report: 95-4227.

Pasteris, J.D., Wopenka, B., Valsami-Jones, E., 2008. Bone and tooth mineralization: why apatite? Elements, 4: 97-104.

Puzio, B., Manecki, M., Kwaśniak-Kominek, M., 2018. Transition from endothermic to exothermic dissolution of hydroxyapatite $\mathrm{Ca}_{5}\left(\mathrm{PO}_{4}\right)_{3} \mathrm{OH}$ - johnbaumite $\mathrm{Ca}_{5}\left(\mathrm{AsO}_{4}\right)_{3} \mathrm{OH}$ solid solution series at temperatures ranging from 5 to $65^{\circ} \mathrm{C}$. Minerals, 8: 1-21.

Rakovan, J.F., J.D., Pasteris, 2015. A technological gem: materials, medical, and environmental mineralogy of apatite. Elements, 11: 195-200.

Scheckel, K.G., Ryan, J.A., 2002. Effects of aging and pH on dissolution kinetics and stability of chloropyromorphite. Environmental Science and Technology, 36: 2198-2204.

Schindler, M., Hawthorne, F.C., Baur, W.H., 2000. A crystal-chemical approach to the composition and occurrence of vanadium minerals. Canadian Mineralogist, 38: 1443-1456.

Shannon, R.D., Calvo, C., 1973. Refinement of the crystal structure of synthetic chervetite, $\mathrm{Pb}_{2} \mathrm{~V}_{2} \mathrm{O}_{7}$. Canadian Journal of Chemistry, 51: 70-76.

Solecka, U., Bajda, T., Topolska, J., Zelek-Pogudz, S., Manecki M., 2018. Raman and Fourier transform infrared spectroscopic study of pyromorphite-vanadinite solid solutions. Spectrochimica Acta Part A: Molecular and Biomolecular Spectroscopy, 190: 96-103.

Sordyl, J., Puzio, B., Manecki, M., 2017. Quantitative determination of Ostwald ripening of mimetite. Mineralogia - Special Papers, 47: 53.

Topolska, J., Borowicz, P., Manecki, M., Bajda, T., Kaschabek, S., Merkel, B.J., 2013. The effect of gluconic acid secretion by phosphate-solubilizing Pseudomonas putida bacteria on dissolution of pyromorphite $\mathrm{Pb}_{5}\left(\mathrm{PO}_{4}\right)_{3} \mathrm{Cl}$ and $\mathrm{Pb}$ remobilization. Annales Societatis Geologorum Poloniae, 83: 343-351.

Topolska, J., Latowski, D., Kaschabek, S., Manecki, M., Merkel, B.J., Rakovan, J., 2014. Pb remobilization by bacterially mediated dissolution of pyromorphite $\mathrm{Pb}_{5}\left(\mathrm{PO}_{4}\right)_{3} \mathrm{Cl}$ in presence of phosphate-solubilizing Pseudomonas putida. Environmental Science and Pollution Research, 21: 1079-1089.

Topolska, J., Manecki, M., Bajda, T., Borkiewicz O., Budzewski, P., 2016. Solubility of pyromorphite $\mathrm{Pb}_{5}\left(\mathrm{PO}_{4}\right)_{3} \mathrm{Cl}$ at $5-65^{\circ} \mathrm{C}$ and its experimentally determined thermodynamic parameters. Journal of Chemical Thermodynamics, 98: 282-287. 